\title{
Effect of Di(2-ethylhexyl)phthalate on
} Helicobacter pylori-Induced Apoptosis in AGS Cells

\author{
Chuang-Hao Lin, ${ }^{1}$ Chien-Yi Wu, ${ }^{2}$ Hwang-Shang Kou, ${ }^{3}$ Chiao-Yun Chen, ${ }^{4}$ \\ Meng-Chuan Huang, ${ }^{5}$ Huang-Ming $\mathrm{Hu}^{6,7}$ Meng-Chieh Wu, ${ }^{8}$ Chien-Yu Lu, ${ }^{6,7}$ \\ Deng-Chyang $\mathrm{Wu}^{6,7,8,9}$ Ming-Tsang $\mathrm{Wu}^{6}{ }^{10}$ and Fu-Chen $\mathrm{Kuo}^{10,11,12}$
}

\author{
${ }^{1}$ Department of Physiology, College of Medicine, Kaohsiung Medical University, Kaohsiung City 807, Taiwan \\ ${ }^{2}$ Department of Pediatrics, E-Da Hospital, Kaohsiung City 824, Taiwan \\ ${ }^{3}$ School of Pharmacy, Kaohsiung Medical University, Kaohsiung City 807, Taiwan \\ ${ }^{4}$ Department of Medical Imaging, Kaohsiung Medical University Hospital, Kaohsiung City 807, Taiwan \\ ${ }^{5}$ Department of Nutritional Sciences, Kaohsiung Medical University Hospital, Kaohsiung, Taiwan \\ ${ }^{6}$ Division of Gastroenterology, Department of Internal Medicine, Kaohsiung Medical University Hospital, \\ Kaohsiung City 807, Taiwan \\ ${ }^{7}$ Department of Medicine, Faculty of Medicine, College of Medicine, Kaohsiung Medical University, Kaohsiung City 807, Taiwan \\ ${ }^{8}$ Department of Internal Medicine, Kaohsiung Municipal Hsiao-Kang Hospital, Kaohsiung City 812, Taiwan \\ ${ }^{9}$ Cancer Center, Kaohsiung Medical University Hospital, Kaohsiung City 807, Taiwan \\ ${ }^{10}$ Graduate Institute of Public Health, Kaohsiung Medical University, Kaohsiung City 807, Taiwan \\ ${ }^{11}$ Department of Obstetrics and Gynecology, E-Da Hospital, Kaohsiung 824, Taiwan \\ ${ }^{12}$ School of Medicine, College of Medicine, I-Shou University, Kaohsiung City 840, Taiwan
}

Correspondence should be addressed to Fu-Chen Kuo; ed100418@edah.org.tw

Received 19 July 2013; Accepted 31 October 2013

Academic Editor: Lin-Li Chang

Copyright (C) 2013 Chuang-Hao Lin et al. This is an open access article distributed under the Creative Commons Attribution License, which permits unrestricted use, distribution, and reproduction in any medium, provided the original work is properly cited.

Plastic products are wildly used in human life. Di(2-ethylhexyl)phthalate (DEHP) is an essential additive in plastic manufacturing and is used as plasticizer for many products including plastic food packaging. DEHP is a teratogenic compound and can cause potent reproductive toxicity. DEHP can also cause liver damage, peroxisome proliferation, and carcinogenesis. DEHP is also strongly associated with peptic ulcers and gastric cancer; however, the underlying effect and mechanism of DEHP on the gastrointestinal tract are not entirely clear. The oral infection route of $H$. pylori parallels the major ingestion route of DEHP into the human body. Therefore, we wanted to study the effect of DEHP and H. pylori exposure on the human gastric epithelial cell line, AGS (gastric adenocarcinoma). The viability of the AGS cell line was significantly lower in $80 \mu \mathrm{M}-\mathrm{DEHP}$ and $H$. pylori $(\mathrm{MOI}=100: 1)$ coexposure than DEHP or H. pylori alone. DEHP and H. pylori coexposure also induced caspase-3 activation, and increased Bax/Bcl-2 ratio and DNA fragmentation in AGS cells. These results indicate that DEHP can enhance $H$. pylori cytotoxicity and induce gastric epithelial cell apoptosis. Therefore, it is possible that DEHP and H. pylori coexposure might enhance the disruption of the gastric mucosa integrity and potentially promote the pathogenesis of gastric carcinogenesis.

\section{Introduction}

Di(2-ethylhexyl)phthalate (DEHP) is the most common plasticizer used to increase the flexibility of polyvinyl chloride (PVC). DEHP is often used for the development of flexible plastics in food-packaging, plastic flooring, carpet material, roofing materials, plastic wall treatments, indoor decorations, wire, cable packaging materials, and children's toys [1]. DEHP is also used as a cleaner, industrial solvent, wetting agent, and lubricant [2]. Human exposure to DEHP usually occurs through air, water, or skin contact with DEHP-contained plastics [3]; however, the most common source of exposure 
is due to the ingestion of contaminated packaged foods. Due to its chemical structure, DEHP can readily dissolve and seep from the packaging materials into the food [2-4].

Phthalate exposure can have many potential health effects in humans. For example, a previous study reported that DEHP and mono-2-ethylhexyl phthalate (MEHP) can pass through the placenta and shorten the gestational period of a developing fetus [5]. DEHP also delays the development of the male reproductive system [2]. Recent evidences also show prenatal DEHP exposure is associated with shorter gestation [6], but prenatal DEHP exposure does not affect birth outcomes [7]. Even though oral ingestion of DEHP is one of the most common routes of exposure in humans, the effects of this toxin on gastric epithelial cells have not been fully elucidated.

The human gastric pathogen, Helicobacter pylori $(H$. pylori), is a spiral Gram-negative microaerophilic bacterium, which can selectively colonize the mucus layer of the stomach and can cause severe gastric problems including the development of chronic gastritis, peptic ulcers, and gastric cancer [8]. $H$. pylori is often transmitted to human through a variety of ways, including oral-oral and fecal-oral routes [9]. H. pylori infection induces apoptosis, of gastric epithelial cells, an effect which was reported with both in vivo $[10,11]$ and in vitro studies [12-14].

Plastics are widely used in food packaging in Taiwan and the world; however, DEHP exposure is often higher in the Taiwanese population than other countries such as in Germany or the US $[15,16]$. H. pylori infection occurs in approximately $50 \%$ of the world's population. The Taiwanese population has as a 54.4\% antibody seropositivity against $H$. pylori [17], which is higher than the H. pylori seropositivity in other countries, such as Ireland [18]. Taken together, these data demonstrate that the high exposure rate of DEHP and high infection rate of $H$. pylori in the Taiwanese people, as well as with the rest of the world, are likely an important health concern; however, the effect of DEHP and $H$. pylori coexposure on gastric epithelial cells is not well understood. For this reason, the effect of DEHP and $H$. pylori coexposure on gastric epithelial cell apoptosis, as an indicator of reduced epithelial cell integrity, was investigated in this study.

\section{Materials and Methods}

2.1. Cell Culture. A human gastric epithelial cell line, AGS (gastric adenocarcinoma. BCRC 60102), was purchased from the Cell Bank of the Taiwan National Health Research Institute and was grown in RPMI 1640 medium supplemented with $10 \%$ fetal bovine serum, $100 \mathrm{U} / \mathrm{mL}$ penicillin, and $100 \mu \mathrm{g} / \mathrm{mL}$ streptomycin or $0.1 \%$ gentamicin (Hyclone, Logan, UT, USA). AGS cells were seeded at densities of 2 2.5 $\times 10^{5} / 35$-mm culture dish or $5 \sim 5.5 \times 10^{5} / 25 \mathrm{~T}$ flask, incubated for $24 \mathrm{hr}$, and switched to culture medium containing 0 $80 \mu \mathrm{M}$ DEHP (CAS number: 117-81-7, Sigma-Aldrich, St. Louis, MO, USA). DEHP has limited solubility in water; a stock solution of DEHP was prepared in DMSO and subsequently diluted to various concentrations with cell culture medium. The final concentration of DMSO in culture medium was approximately $1 \%$ and had no significant effect on cell viability. All cultures were grown in a humidified incubator at $37^{\circ} \mathrm{C}$ and in an atmosphere of $95 \%$ air- $5 \% \mathrm{CO}_{2}$.

2.2. H. pylori Culture. Due to the role of cytotoxin associated gene A (CagA) and vacuolating cytotoxin A (VacA) genes, genes commonly associated with $H$. pylori associated gastric cell apoptosis [19], the CagA/VacA positive H. pylori strain ATCC 43054, purchased from the Cell Bank of the Taiwan National Health Research Institute, was used for this study. ATCC 43054 was cultured on trypticase soy agar with 5\% sheep's blood (Curtin Matheson, Jessup, MD, USA) with Skirrow's selective antibiotic supplement (Prolab Inc., Scarborough, Canada) at $37^{\circ} \mathrm{C}$ in a $\mathrm{CO}_{2} / \mathrm{O}_{2}$ water jacketed incubator (Forma Scientific, Marietta, OH, USA) under microaerophilic conditions $\left(10 \% \mathrm{CO}_{2}, 7.5 \% \mathrm{O}_{2}, 82.5 \% \mathrm{~N}_{2}\right)$. $H$. pylori were added to cells at a bacterium: cellular concentration range (Multiplicities of infection, MOI) of $100: 1$ to $25: 1$. $H$. pylori was used between passages 5 and 15 for these experiments to ensure that the bacteria were able to readily adhere to AGS cells. Adherence was visualized using microscopy.

2.3. Cell Viability Assay. AGS cells were seeded in 48-well culture plates at a density of 100 cells $/ \mathrm{mm}^{2}$, allowed to grow for $24 \mathrm{hr}$, and switched to culture media containing DEHP with or without $H$. pylori for 18 to $48 \mathrm{hr}$. For measuring the cell viability, MTT (3-[4,5-dimethylthiazol-2-yl]-2,5diphenyltetrazolium bromide, $0.5 \mathrm{mg} / \mathrm{mL}$; Sigma-Aldrich, St. Louis, MO, USA) was added to each well, and the plates were incubated for 3 hours at $37^{\circ} \mathrm{C}$. The formazan crystals (a product of metabolic activity) were dissolved in isopropyl alcohol with $0.04 \% \mathrm{HCl}$ and the formazan in each well was quantified using a Dynex MRX II spectrophotometer (Dynex Technologies, Chantilly, VA, USA) at absorption frequencies of 540 and $630 \mathrm{~nm}$. The data were pooled from three independent experiments at least, and the number of replicate wells is $\geq 4$.

2.4. DNA Fragmentation Assay. The extent of DNA fragmentation was quantified using the Cell Death Detection ELISA $^{\text {Plus }}$ kit (Roche, Mannheim, Germany) as described in the manufacturer's manual. Briefly, cells were lysed by adding lysis buffer to each well and incubating for $30 \mathrm{~min}$ at $4^{\circ} \mathrm{C}$. Each plate was centrifuged at $200 \times \mathrm{g}$ for $10 \mathrm{~min}$, and $20 \mu \mathrm{L}$ of each supernatant was transferred to streptavidin-coated wells. The wells were treated with an anti-histone- and anti-DNAcontaining immuno-reagent, incubated for $2 \mathrm{hr}$ at room temperature, washed three times, and treated with the peroxidase substrate 2,2' -azino-di-(3-ethyl-benzthiazoline sulfonate). Absorption at $405 \mathrm{~nm}$ was measured using a Dynex MRX II spectrophotometer (Dynex Technologies, Billingshurst, UK).

2.5. Immunoblotting Analysis of Caspase-3, Caspase-8, Bax, and $\mathrm{Bcl}-2$. Cell protein extracts $(20 \mu \mathrm{g})$ were denatured in sodium dodecyl sulfate (SDS) sample buffer at $95^{\circ} \mathrm{C}$ for $5 \mathrm{~min}$, loaded onto 10-20\% gradient SDS-polyacrylamide gel electrophoresis (PAGE) gels (Invitrogen), and separated by electrophoresis. Separated proteins were transferred to a polyvinylidene difluoride (PVDF) membrane. The membrane was blocked with $5 \%$ nonfat milk in Tris-buffered saline 


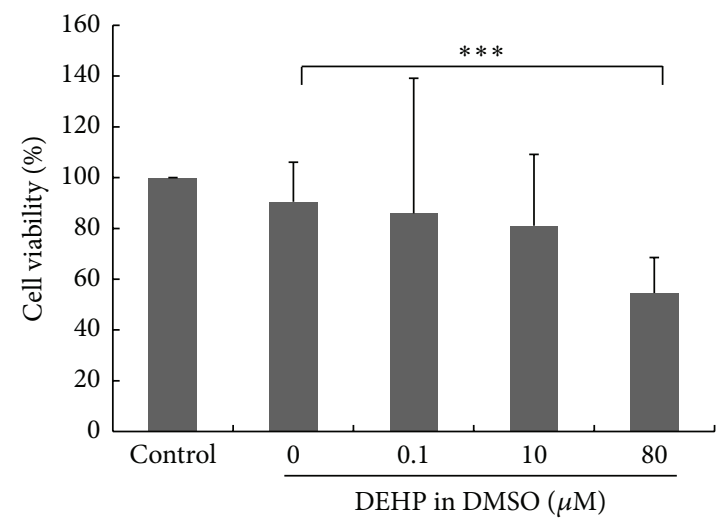

(a)

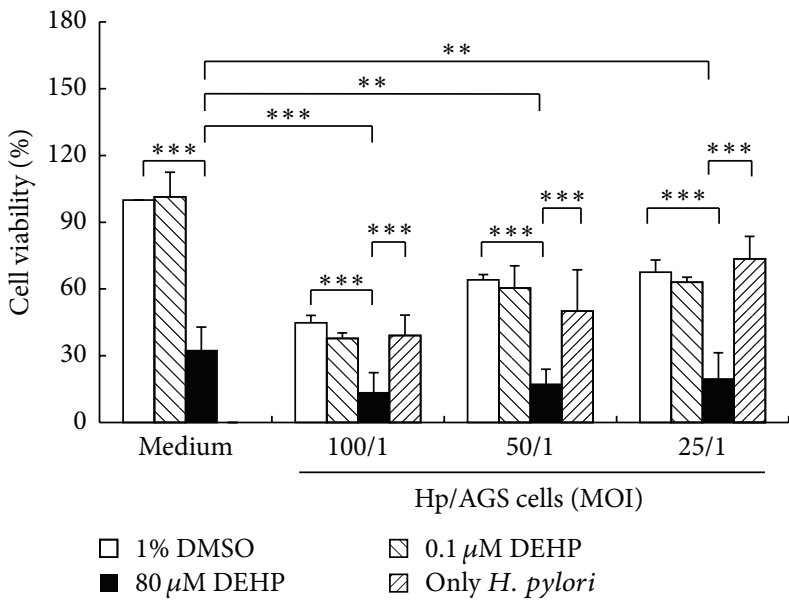

(b)

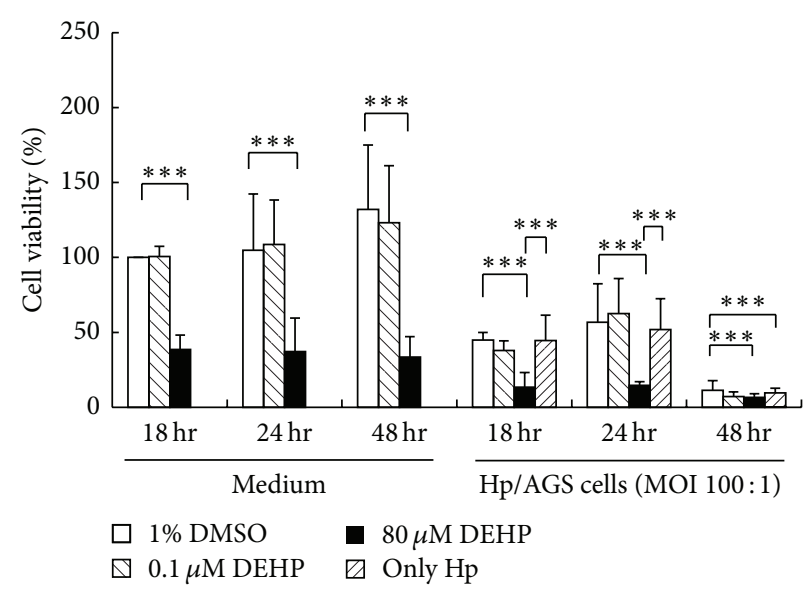

(c)

FIgURE 1: The cell viability of AGS cell. (a) Cells were treated with 0.1 to $80 \mu \mathrm{M}$ DEHP for 24 hours. (b) Cells were treated 0.1 and $80 \mu \mathrm{M}$ DEHP alone or combined with $H$. pylori (MOI $=100: 1 \sim 25: 1$ ) for 18 hours (ten independent experiments). (c) Cells were treated 0.1 and $80 \mu \mathrm{M}$ DEHP alone or combined with $H$. pylori $(\mathrm{MOI}=100: 1)$ for 18,24 , and 48 hours Values obtained from MTT assay in mean + SD and normalized to nontreated value $\left(N=7\right.$, three independent experiments, ${ }^{* *} P<0.05,{ }^{* * *} P<0.01$, one way ANOVA assay with LSD post hoc test).

(TBS) containing $0.05 \%$ Tween-20 and treated with antibodies against active caspase- 3 (rabbit polyclonal antiactive caspase-3 antibody, 1:500, Abcam, Cambridge, MA, USA), active caspase- 8 (rabbit polyclonal antiactive caspase- 8 antibody, 1:1000, Abcam,), Bax (mouse polyclonal anti-Bax antibody, 1:500, Santa Cruz Biotechnology (SCBT), Santa Cruz, $\mathrm{CA}, \mathrm{USA}), \mathrm{Bcl}-2$ (mouse polyclonal anti-Bcl-2 antibody, 1:500, SCBT), GAPDH (chicken polyclonal anti-GAPDH antibody, $1: 1000$, Millipore, Billerica, MA, USA) and $\beta$-actin (mouse monoclonal anti- $\beta$-actin antibody, $1: 1000$, SCBT). Bound antibodies were detected using HRP-conjugated secondary antibodies (1:5000, Jackson ImmunoResearch Laboratories; West Grove, PA, USA) and enhanced chemiluminescence (ECL, Amersham Pharmacia Biotech, Piscataway, NJ, USA). Densitometric images of blots were visualized on a BioSpectrum AC Imaging System (UVP, Upland, CA, USA) and were analyzed using Vision WorksLS analysis software.
2.6. Statistical Analysis. At least triplicate experiments were performed for each set of operating conditions. The quantitative data are expressed as mean \pm SD Statistics were performed using SigmaStat 3.5 (SysStat Software, San Jose, CA, USA). Differences between study and control groups were evaluated by analysis of variance (ANOVA). The level of significance for differences between groups was further analyzed using post hoc Fisher's least significant difference (LSD) tests. A $P<0.05$ was defined as statistically significant.

\section{Result}

3.1. DEHP and H. pylori Coexposure Reduced Cell Viability of AGS Cells. The cell viability of AGS cells after DEHP treatment for $24 \mathrm{hr}$ is shown in Figure 1(a). Cell viability was significantly decreased after an exposure of $80 \mu \mathrm{M}$ of DEHP treatment (one way ANOVA, $P<0.001$ ). The $0.1 \mu \mathrm{M}$ $(P=0.486), 1 \mu \mathrm{M}(P=0.215)$, and $10 \mu \mathrm{M}(P=0.375)$ 
of DEHP also induced a nonsignificant decrease in AGS cell viability, when compared with a DMSO (vehicle) group and tested by one way ANOVA. Additionally, no significant statistical difference (one way ANOVA, $P=0.427$ ) was observed between control (culture medium without DMSO) and vehicle group. Since the DEHP- $80 \mu \mathrm{M}$ caused the most significant decrease in cell viability, this concentration was utilized for further experiments.

AGS cell viability after DEHP and $H$. pylori coexposure are presented in Figure 1(b). Cell viability was significantly reduced by DEHP- $80 \mu \mathrm{M}$ for $18 \mathrm{hr}$ (one way ANOVA, $P<$ 0.01). H. pylori infection significantly increased AGS cell death in a (multiplicity of infection) MOI-dependent manner. Compared with vehicle or $H$. pylori alone, DEHP- $80 \mu \mathrm{M}$ and $H$. pylori coexposure significantly reduced the cell viability of AGS cell after an $18 \mathrm{hr}$ exposure (one way ANOVA, $P<0.01$ ). Compared with DEHP- $80 \mu \mathrm{M}$ alone, DEHP- $80 \mu \mathrm{M}$ and $H$. pylori coexposure also significantly reduced the cell viability of AGS cell after $H$. pylori $(\mathrm{MOI}=100 / 1)$ coexposure (one way ANOVA, $P<0.01$ ). Not only does this result imply a cytotoxic effect of DEHP and H. pylori alone on AGS cells, but it also indicates that the combined DEHP and H. pylori exposure has an additive cytotoxic effect on AGS cells. Since the cytotoxicity of $H$. pylori at a MOI of 100/1 when combined with DEHP was higher than at MOI of 50/1 and MOI of $25 / 1$, this experimental condition was used for further studies. In addition, there was no significantly statistical difference in cell viability between the groups of $H$. pylori in DMSO (vehicle) and $H$. pylori (MOI $=100: 1,50: 1$ and 25:1) in culture medium (one way ANOVA, $P=0.613, P=0.149$, and $P=0.452$ resp.).

A time-course study of AGS cell viability changes after DEHP and $H$. pylori coexposure are shown in Figure 1(c). The cell viability was significantly decreased in a time-dependent manner by DEHP- $80 \mu \mathrm{M}$ treatment (one way ANOVA, $P<$ $0.01)$. DEHP- $80 \mu \mathrm{M}$ and $H$. pylori (MOI $=100: 1)$ coexposure more significantly decreased AGS cell viability. Because almost cells (about $87 \%$ ) were dead after $18 \mathrm{hr}$ of exposure and cell viability was not significantly statistical difference between $18 \mathrm{hr}$ and $24 \mathrm{hr}$ after DEHP- $80 \mu \mathrm{M}$ and $H$. pylori coexposure (one way ANOVA, $P=0.674$ ), therefore, DEHP and $H$. pylori treatment for $18 \mathrm{hr}$ was selected for further experiments.

3.2. DEHP and H. pylori Coexposure-Induced Apoptosis of AGS Cells. The Cell Death Detection ${ }^{\text {Plus }}$ system (Roche) was used to detect AGS cell apoptosis (Figure 2). DEHP dose dependently induced a nonsignificant increase in the ratio of DNA fragmentation. Compared with a vehicle group, an $18 \mathrm{hr}$ exposure of DEHP- $80 \mu \mathrm{M}$ exhibited a nonsignificant tendency to increase the DNA fragmentation ratio (oneway ANOVA, $P=0.059$ ). DEHP and $H$. pylori (MOI of 100/1) coexposure for $18 \mathrm{hr}$, however, significantly increased the DNA fragmentation ratio (one-way ANOVA, $P<0.01$ ). The ratio of DNA fragmentation after DEHP- $80 \mu \mathrm{M}$ and $H$. pylori coexposure was significantly higher than DEHP (oneway ANOVA, $P<0.01$ ) or $H$. pylori alone (one-way ANOVA, $P<0.01)$. This result implies that DEHP can enhance the toxicity of $H$. pylori and increase $H$. pylori-induced apoptosis

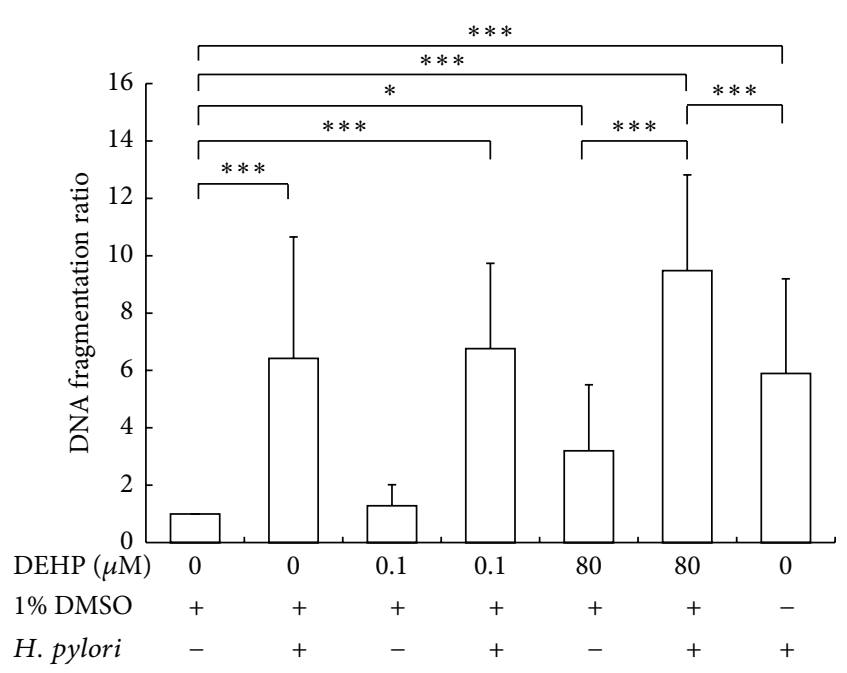

Figure 2: DEHP and $H$. pylori $(\mathrm{MOI}=100: 1)$ exposure induced DNA fragmentation of AGS cells. The level of apoptosis occurring with each treatment was determined by cell death ELISA ${ }^{\text {Plus }}$ kit. Statistical significance was analyzed by one-way ANOVA and post hoc LSD test $\left({ }^{*} P<0.1,{ }^{* *} P<0.05,{ }^{* * *} P<0.01, N=4\right)$.

of AGS cells. Additionally, the ratio of $H$. pylori-induced DNA fragmentation did not exhibit a significant difference in DMSO-containing or normal medium, which indicates the activity and toxicity of $H$. pylori were not affected by DMSO.

3.3. DEHP and H. pylori Coexposure Increased Bax/Bcl-2 Ratio. Expression of Bax and Bcl-2 protein after DEHP and H. pylori treatment for 3 hours was detected by Western blot analysis and the Bax/Bcl-2 ratio was calculated. DEHP$80 \mu \mathrm{M}$ (one way ANOVA, $P<0.05$ ) or $H$. pylori treatment alone (one way ANOVA, $P<0.05$ ) increase Bax/Bcl-2 ratio; however, the combined treatment of DEHP- $80 \mu \mathrm{M}$ and $\mathrm{H}$. pylori coexposure caused a much higher $\mathrm{Bax} / \mathrm{Bcl}-2$ ratio increase (one way ANOVA, $P<0.05$ ) (Figure 3). This result implied that DEHP and H. pylori coexposure disturbed the balance between $\mathrm{Bax}$ and $\mathrm{Bcl}-2$ protein expression.

3.4. Effect of DEHP and H. pylori Coexposure on Expression of the Active Forms of Caspase-3 and Caspase-8. Expression of active caspase- 3 and caspase- 8 protein after $18 \mathrm{hr}$ DEHP and $H$. pylori treatment was quantified by Western blot analysis and the results are presented in Figures 4 and 5 . Expression of active caspase-3 was significantly increased after $H$. pylori/DEHP co-exposure, especially with DEHP$80 \mu \mathrm{M}$ combined with $H$. pylori treatment (one way ANOVA, $P<0.01$, compared with vehicle group) (Figure 4). DEHP$80 \mu \mathrm{M} / H$. pylori co-exposure-induced active caspase- 3 protein expression, which was also higher than DEHP- $80 \mu \mathrm{M}$ (one way ANOVA, $P<0.05$ ) or $H$. pylori alone (one way ANOVA, $P<0.05)$. Active caspase-8 expression was not significantly changed after $18 \mathrm{hr}$ DEHP or $\mathrm{H}$. pylori (one way ANOVA, $P>0.1$ ) (Figure 5). The ratio of these apoptosisrelated proteins also was summarized in Table 1 with mean \pm SD. 

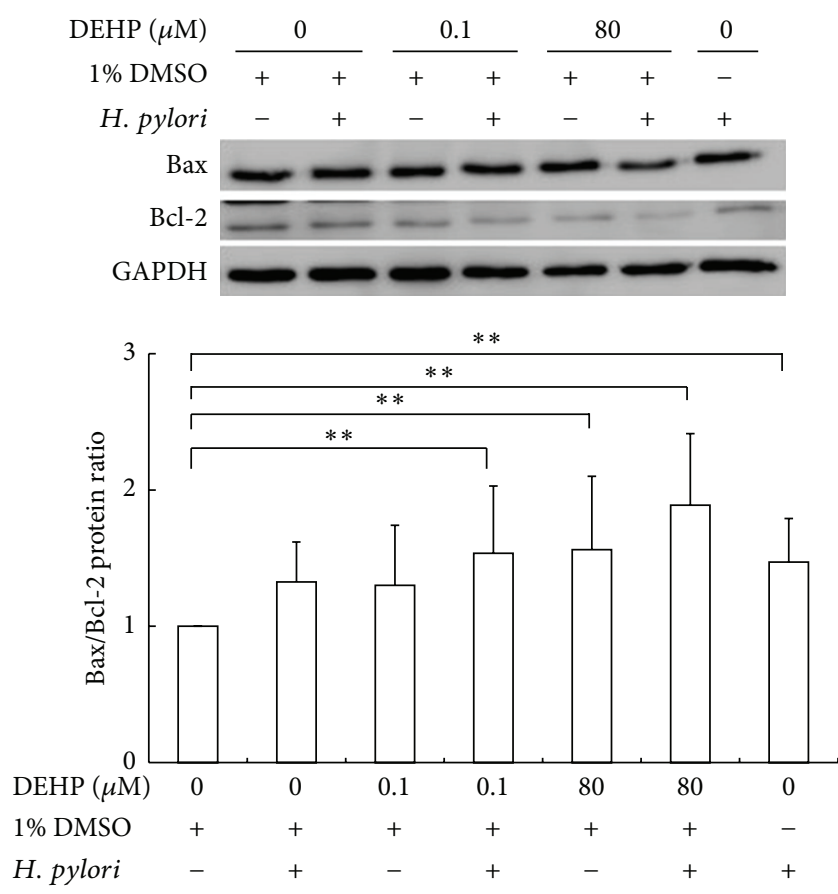

Figure 3: DEHP and H. pylori exposure for 3 hours changed the $\mathrm{Bax} / \mathrm{Bcl}-2$ ratio of AGS cells. Statistical significance was analyzed by one-way ANOVA and post hoc LSD test $\left({ }^{* *} P<0.05, N=4\right)$.

\section{Discussion}

Helicobacter pylori (H. pylori) bacterium was first identified and isolated from gastric biopsies of patients with gastritis and peptic ulcers [20]. The NIH Consensus Development Conference [21] identified $H$. pylori as the primary reason for peptic ulcer development. $H$. pylori was also evaluated by the International Agency for Research on Cancer (IARC) and was identified as a human Group 1 carcinogen (1994). H. pylori is associated with both gastric adenocarcinoma and gastric lymphomas. H. pylori is transmitted to humans through a variety of ways, including oral-oral and fecal-oral routes [9].

DEHP is a plasticizer found widely in food packaging, which often can migrate from the plastic wrapping and actually contaminate the packaged food [22]. DEHP contamination is prevalent throughout the food chain [23]. Meat, fish, dairy products, fresh fruit, and bread all exhibited $100 \%$ prevalence for DEHP contamination. Other important foods also exhibited a prevalence for DEHP contamination to a lesser extent; cereals and legumes (93\%), vegetables (80\%), and condiments (66\%) [24]. The estimated daily intake of phthalates in the general Taiwanese population is approximately 0.1 to $309.6 \mu \mathrm{g} / \mathrm{kgBW} /$ day (about 0.015 to $47.5 \mu \mathrm{M}$ by a $60 \mathrm{~kg}$ adult) [15]. With PVC industry workers, the daily intake of phthalates is much higher at about $0.6-850 \mu \mathrm{g} / \mathrm{kgBW} /$ day (about 0.092 to $130.6 \mu \mathrm{M}$ by a $60 \mathrm{~kg}$ adult) [25]. Since the half-life of DEHP in the human body ranges between 16 and 24 hours [26], DEHP may be able to stimulate the epithelial cells of the gastrointestinal tract and accumulate in the human body via sustainably ingested of DEHP-contaminated foods. In humans, ingestion of 10 grams of DEHP $(\sim 426 \mu \mathrm{M}$,
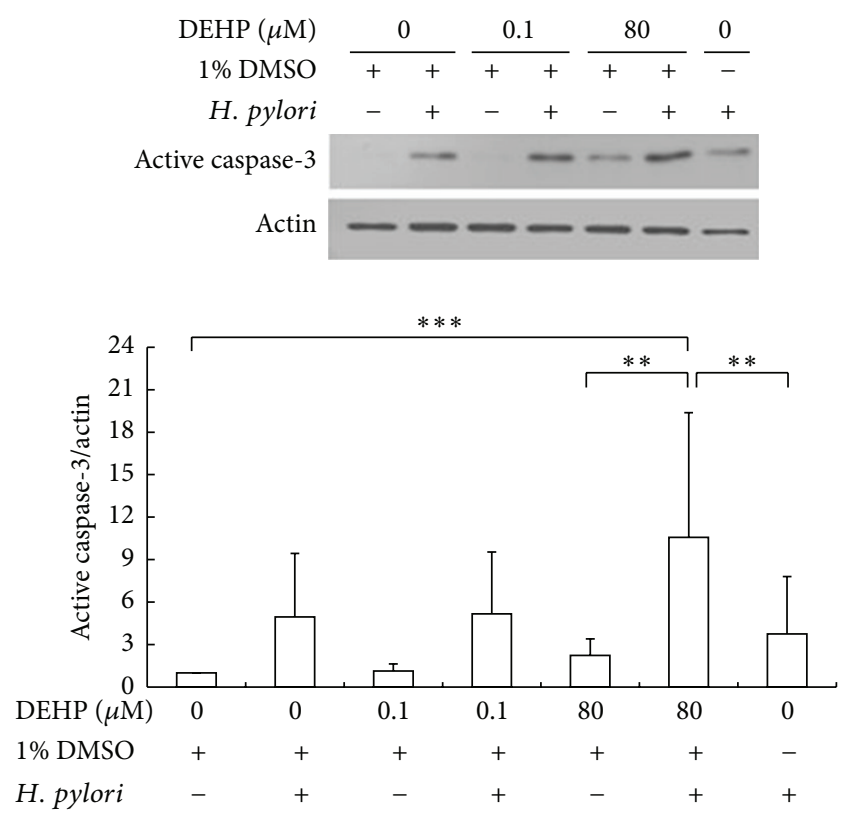

FIgURE 4: DEHP and H. pylori increased active form of caspase-3 protein expression after 18-hour treatment. Statistical significance was analyzed by one-way ANOVA and post hoc LSD test $\left({ }^{* *} P<\right.$ $\left.0.05,{ }^{* * *} P<0.01, N=4\right)$.

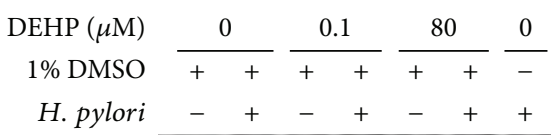

Active caspase-8

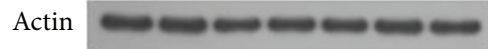

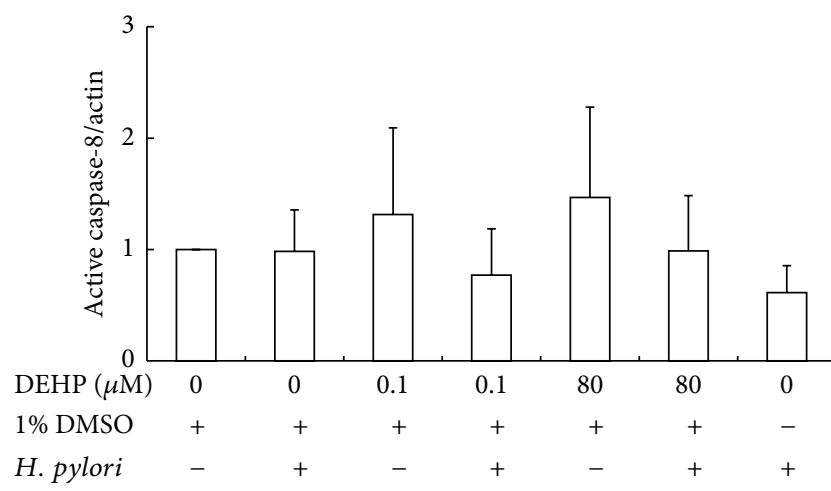

FIgURE 5: The effect of DEHP and $H$. pylori on active caspase- 8 protein expression after 18-hour treatment. Statistical significance was analyzed by one-way ANOVA and post hoc LSD test $(N=3)$.

assuming $60 \mathrm{~kg}$ b.w.) can cause mild gastric disturbances and "moderate catharsis" [27]; however, the effects of short and long term high level exposure to DEHP are not known. In this study, the effects of $H$. pylori and DEHP were identified on gastric epithelial cells. We found that DEHP and $H$. pylori coexposure decreased AGS cell viability greater than DEHP or H. pylori alone (Figure 1), indicating that the combined exposure of $H$. pylori and DEHP has additive toxic effects on 
TABLE 1: Summary of apoptosis-related proteins expression ratio after DEHP alone or DEHP combined with H. pylori $($ MOI $=100: 1)$ treatment ${ }^{\mathrm{a}}$.

\begin{tabular}{|c|c|c|c|c|c|c|c|c|}
\hline \multirow[t]{2}{*}{ Ratio } & \multirow[t]{2}{*}{$N$} & & \multicolumn{2}{|c|}{$\begin{array}{c}\text { Medium } \\
(1 \% \mathrm{DMSO})\end{array}$} & \multicolumn{2}{|c|}{$\begin{array}{l}\text { Medium } \\
(1 \% \text { DMSO) + } \\
\text { Hp/AGS cells } \\
(\text { MOI } 100: 1)\end{array}$} & \multicolumn{2}{|c|}{$\begin{array}{l}\text { Medium } \\
\text { (w/o DMSO) + } \\
\text { Hp/AGS cells } \\
(\text { MOI } 100: 1)\end{array}$} \\
\hline & & & Mean & SD & Mean & $\mathrm{SD}$ & Mean & SD \\
\hline \multirow{4}{*}{ Active caspase-3/actin } & \multirow{4}{*}{4} & Vehicle & 1.00 & 0.00 & 4.95 & 4.49 & & \\
\hline & & $0.1 \mathrm{uM}$ DEHP & 1.14 & 0.50 & 5.17 & 4.36 & & \\
\hline & & 80 uM DEHP & 2.23 & 1.17 & 10.57 & 8.81 & & \\
\hline & & Only H. pylori & & & & & 3.75 & 4.05 \\
\hline \multirow{4}{*}{ Active caspase-8/actin } & \multirow{4}{*}{3} & Vehicle & 1.00 & 0.00 & 0.98 & 0.37 & & \\
\hline & & $0.1 \mathrm{uM}$ DEHP & 1.31 & 0.78 & 0.77 & 0.42 & & \\
\hline & & 80 uM DEHP & 1.47 & 0.81 & 0.99 & 0.50 & & \\
\hline & & Only H.pylori & & & & & 0.61 & 0.24 \\
\hline \multirow{4}{*}{$\mathrm{Bax} / \mathrm{Bcl}-2$} & \multirow{4}{*}{5} & Vehicle & 1.00 & 0.00 & 1.33 & 0.29 & & \\
\hline & & $0.1 \mathrm{uM}$ DEHP & 1.30 & 0.44 & 1.54 & 0.49 & & \\
\hline & & 80 uM DEHP & 1.56 & 0.54 & 1.89 & 0.53 & & \\
\hline & & Only H. pylori & & & & & 1.47 & 0.32 \\
\hline
\end{tabular}

${ }^{\mathrm{a}}$ The protein expression ratio was normalized to vehicle group.

gastrointestinal epithelial cells, potentially altering the ratio between cell proliferation and apoptosis.

The imbalance between cell proliferation and apoptosis may contribute to gastric carcinogenesis. Gastric resection specimens from patients that exhibited normal gastric mucosa contained a low number of apoptotic cells at the surface epithelium. The apoptotic number was significantly increased in cases with chronic gastritis and/or intestinal metaplasia [28]. Increased apoptosis is associated with the development of gastric carcinoma [29]. The TUNEL assay on biopsies obtained from the gastric mucosa in patient with gastric carcinoma also found multiple apoptotic cells [30]. In addition, it has been shown that the increase rate of $H$. pyloriinduced apoptosis on AGS cell line was $47.0 \%$ and on a normal gastric epithelial cell line (GES-1), which is developed by Beijing Institute for Cancer Research Collection, was 113.0\% [31], the flow cytometry experiment also showed the ratio of apoptosis in GES-1 cells was 10.2\% 27.6\% after $H$. pylori infection for 4 hours [32], and the ratio of apoptosis in AGS cells was about $18 \%$ after $H$. pylori infection for 6 hours [33]. These articles indicated that normal gastric epithelial cell might be more sensitive than AGS cell to $H$. pylori and could cause higher ratio apoptosis than AGS cell after $H$. pylori infection. Because apoptosis ratio increase is one of the possible pathways which associated with the development of gastric carcinoma [29], H. pylori-induced carcinogenesis might be more evident on normal gastric epithelial cell than AGS cells. In this study, we found that H. pylori and DEHP coexposure increased DNA fragmentation of AGS cells (Figure 2). This result implies that $H$. pylori and DEHP coexposure might induce cell apoptosis and alter the balance between cell proliferation and cell death in gastric epithelial cells, disrupting the integrity of the gastric mucosa and promoting gastric carcinogenesis. Moreover, the ratio of $H$. pylori and DEHP coexposure was higher than $H$. pylori infection alone, further indicating that DEHP enhances $H$. pylori-induced apoptosis on AGS cells. Apoptosis has been shown that, related with the cell subpopulations of highly growth rate selection in gastric precancerous lesions and involved in the malignant transformation [34], H. pylori is type I carcinogen and DEHP is type 2B carcinogen in IARC classification (2000); moreover, we found DEHP and $H$. pylori exposure increased AGS cell apoptosis. Therefore, DEHP and H. pylori-induced AGS cell apoptosis might increase the AGS cell malignant transformation.

Previous articles also revealed that apoptosis-related proteins expression was different in various types of gastric precancerous lesions and might involve in the process of carcinogenesis and metastasis. Bcl-2 protein expression was increased in gastric premalignant lesions and decreased its expression after malignant change [34, 35]. Bax protein expression was upregulated in patient's gastric precancerous lesions after H. pylori infection [36]. Bax protein is also highly expressed in intestinal metaplasia regions nearby to tumors and related with induction of apoptosis [35]. Bax protein was found highly expression in gastric cancer patient's tissues and there was no difference in the tumor stage [37]. Taken together, the $\mathrm{Bax} / \mathrm{Bcl}-2$ ratio of cancer cell might increase after malignant change. Our results show that combined exposure of DEHP and $H$. pylori increased the $\mathrm{Bax} / \mathrm{Bcl}-2$ ratio of AGS cell (Figure 3), this result might imply DEHP, and $H$. pylori exposure might induce AGS cell malignant change.

Apoptosis includes two separate pathways: intrinsic and extrinsic. The intrinsic pathway is induced by the permeability loss of the mitochondrial outer membrane. The permeability loss of the mitochondrial outer membrane leads to cytochrome c release, apoptosome formation, and procaspase- 9 
activation. The extrinsic pathway is initiated by extracellular death ligand binding, which results in the activation of caspase- 8 . Both the intrinsic and extrinsic pathways activate caspase-3 and result in apoptosis [38, 39]. H. pylori was reported to induce gastric epithelial cell apoptosis through the activation of the extrinsic pathway [40]; however, in a different study, $H$. pylori was also reported to induce apoptosis mainly through the intrinsic pathway. Caspase- 8 activation did not appear to play a major role in $H$. pylori induced apoptosis [41]. In this study, the DEHP and H. pylori coexposure significantly increased activated caspase-3 in AGS cells (Figure 4), but caspase- 8 activation was not changed after an $18 \mathrm{hr}$ exposure (Figure 5). This result is similar to previously reviewed articles, indicating that caspase- 8 is not essential for DEHP or H. pylori-induced apoptosis and that DEHP and $H$. pylori-induced apoptosis is also likely mediated by the intrinsic pathway. Additionally, active caspase- 3 was significantly higher in cells that were co-exposed to DEHP and $H$. pylori than cells exposed to DEHP or H. pylori alone. These results paralleled the DNA fragmentation study, indicating DEHP and H. pylori coexposure has an additive effect on caspase-3 activation and apoptosis of AGS cells. Moreover, caspase- 3 activation plays an important role in stress-induced invasion [42], high level caspase-3 expression in the tissue sample of gastric cancer patients has been shown poor prognosis and related with gastric cancer lymph node metastasis [43]. The caspase-3 protein expression in primary gastric carcinoma was higher than metastatic gastric carcinomas $[44,45]$. This study found that DEHP and $H$. pylori exposure increased the expression of active form of caspase-3 in AGS cells and induced AGS cells apoptosis, and this result implied that DEHP and $H$. pylori might enhance the ability of stress-induced invasion ability of gastric cancer. Taken together, these data not only indicate that while caspase-3 likely plays an important role in AGS cell apoptosis induced by the combined DEHP and H. pylori exposure, but also imply the additive effect on malignant transformation of AGS cell after DEHP and H. pylori exposure.

In conclusion, this paper reports that DEHP and $H$. pylori coexposure can regulate $\mathrm{Bax}$ and $\mathrm{Bcl}-2$ protein expression to increase $\mathrm{Bax} / \mathrm{Bcl}-2$ ratio, activate caspase- 3 protein, and enhance AGS cellular apoptosis. These results provide new information about the carcinogenetic effect of DEHP and $H$. pylori coexposure on gastric epithelial cells, which may, with further research, suggest a possible mechanism, in which DEHP enhances carcinogenesis when combined with a known carcinogen. Therefore, a further investigation is necessary to understand the underlying mechanism by which DEHP and H. pylori can induce carcinogenesis and metastasis in gastric epithelial cells.

\section{Conflict of Interests}

The authors declare that there is no conflict of interests.

\section{Acknowledgments}

This work was supported by Grants from Kaohsiung Medical University Hospital (KMUH99-9 M68, KMUH100-0 M01),
E-Da Hospital (EDAHP100012, EDAHP101021), Excellence for Cancer Research Center Grant (DOH102-TD-C-111-002), and Department of Health, Executive Yuan, Taiwan.

\section{References}

[1] S. Sathyanarayana, "Phthalates and Children's Health," Current Problems in Pediatric and Adolescent Health Care, vol. 38, no. 2, pp. 34-49, 2008.

[2] R. Kavlock, K. Boekelheide, R. Chapin et al., "NTP center for the evaluation of risks to human reproduction: phthalates expert panel report on the reproductive and developmental toxicity of di(2-ethylhexyl) phthalate," Reproductive Toxicology, vol. 16, no. 5, pp. 529-653, 2002.

[3] J. J. Adibi, F. P. Perera, W. Jedrychowski et al., "Prenatal exposures to Phthalates among women in New York and Krakow, Poland," Environmental Health Perspectives, vol. 111, no. 14, pp. 1719-1722, 2003.

[4] T. Schettler, "Human exposure to phthalates via consumer products," International Journal of Andrology, vol. 29, no. 1, pp. 134-139, 2006.

[5] G. Latini, C. de Felice, G. Presta et al., "In utero exposure to di-(2-ethylhexyl)phthalate and duration of human pregnancy," Environmental Health Perspectives, vol. 111, no. 14, pp. 1783-1785, 2003.

[6] R. M. Whyatt, J. J. Adibi, A. M. Calafat et al., "Prenatal di(2ethylhexyl)phthalate exposure and length of gestation among an inner-city cohort," Pediatrics, vol. 124, no. 6, pp. e1213-e1220, 2009.

[7] Y. Suzuki, M. Niwa, J. Yoshinaga, Y. Mizumoto, S. Serizawa, and H. Shiraishi, "Prenatal exposure to phthalate esters and PAHs and birth outcomes," Environment International, vol. 36, no. 7, pp. 699-704, 2010.

[8] J. G. Kusters, A. H. M. van Vliet, and E. J. Kuipers, "Pathogenesis of Helicobacter pylori infection," Clinical Microbiology Reviews, vol. 19, no. 3, pp. 449-490, 2006.

[9] S. M. Kelly, M. C. L. Pitcher, S. M. Farmery, and G. R. Gibson, "Isolation of Helicobacter pylori from feces of patients with dyspepsia in the United Kingdom," Gastroenterology, vol. 107, no. 6, pp. 1671-1674, 1994.

[10] S. F. Moss, J. Calam, B. Agarwal, S. Wang, and P. R. Holt, "Induction of gastric epithelial apoptosis by Helicobacter pylori," Gut, vol. 38, no. 4, pp. 498-501, 1996.

[11] F. Kacar, I. Meteoğlu, H. Yasa, and E. Levi, "Helicobacter pyloriinduced changes in the gastric mucosa are associated with mitogen-activated protein kinase (MAPK) activation," Applied Immunohistochemistry and Molecular Morphology, vol. 15, no. 2, pp. 224-228, 2007.

[12] G. Chen, E. M. Sordillo, W. G. Ramey et al., "Apoptosis in gastric epithelial cells is induced by Helicobacter pylori and accompanied by increased expression of BAK," Biochemical and Biophysical Research Communications, vol. 239, no. 2, pp. 626632, 1997.

[13] S. H. Chu, J. W. Lim, K. H. Kim, and H. Kim, "NF- $\kappa$ B and Bcl-2 in Helicobacter pylori-induced apoptosis in gastric epithelial cells," Annals of the New York Academy of Sciences, vol. 1010, pp. 568-572, 2003.

[14] I. J. Choi, J. S. Kim, J. M. Kim, H. C. Jung, and I. S. Song, "Effect of inhibition of extracellular signal-regulated kinase 1 and 2 pathway on apoptosis and bcl-2 expression in Helicobacter pylori-infected AGS cells," Infection and Immunity, vol. 71, no. 2, pp. 830-837, 2003. 
[15] M.-L. Chen, J.-S. Chen, C.-L. Tang, and I.-F. Mao, “The internal exposure of Taiwanese to phthalate-an evidence of intensive use of plastic materials," Environment International, vol. 34, no. 1, pp. 79-85, 2008.

[16] P.-C. Huang, P.-L. Kuo, Y.-L. Guo, P.-C. Liao, and C.-C. Lee, "Associations between urinary phthalate monoesters and thyroid hormones in pregnant women," Human Reproduction, vol. 22, no. 10, pp. 2715-2722, 2007.

[17] J.-T. Lin, J.-T. Wang, T.-H. Wang, M.-S. Wu, T.-K. Lee, and C.J. Chen, "Helicobacter pylori infection in a randomly selected population, healthy volunteers, and patients with gastric ulcer and gastric adenocarcinoma. A seroprevalence study in Taiwan," Scandinavian Journal of Gastroenterology, vol. 28, no. 12, pp. 1067-1072, 1993.

[18] L. J. Murray, E. E. McCrum, A. E. Evans, and K. B. Bamford, "Epidemiology of Helicobacter pylori infection among 4742 randomly selected subjects from Northern Ireland," International Journal of Epidemiology, vol. 26, no. 4, pp. 880-887, 1997.

[19] S. Wagner, W. Beil, J. Westermann et al., "Regulation of gastric epithelial cell growth by Helicobacter pylori: evidence for a major role of apoptosis," Gastroenterology, vol. 113, no. 6, pp. 1836-1847, 1997.

[20] B. J. Marshall and J. R. Warren, "Unidentified curved bacilli in the stomach of patients with gastritis and peptic ulceration," The Lancet, vol. 1, no. 8390, pp. 1311-1315, 1984.

[21] "NIH Consensus Conference. Helicobacter pylori in peptic ulcer disease. NIH Consensus Development Panel on Helicobacter pylori in Peptic Ulcer Disease," The Journal of the American Medical Association, vol. 272, no. 1, pp. 65-69, 1994.

[22] M. Sharman, W. A. Read, L. Castle, and J. Gilbert, "Levels of di-(2-ethylhexyl)phthalate and total phthalate esters in milk, cream, butter and cheese," Food Additives and Contaminants, vol. 11, no. 3, pp. 375-385, 1994.

[23] J. H. Petersent and T. Breindahl, "Plasticizers in total diet samples, baby food and infant formulae," Food Additives and Contaminants, vol. 17, no. 2, pp. 133-141, 2000.

[24] T. Cirillo, E. Fasano, E. Castaldi, P. Montuori, and R. Amodio Cocchieri, "Children's exposure to $\mathrm{Di}(2$-ethylhexyl)phthalate and dibutylphthalate plasticizers from school meals," Journal of Agricultural and Food Chemistry, vol. 59, no. 19, pp.10532-10538, 2011.

[25] C. J. Hines, N. B. N. Hopf, J. A. Deddens, M. J. Silva, and A. M. Calafat, "Estimated daily intake of phthalates in occupationally exposed groups," Journal of Exposure Science and Environmental Epidemiology, vol. 21, no. 2, pp. 133-141, 2011.

[26] M. Wittassek and J. Angerer, "Phthalates: metabolism and exposure," International Journal of Andrology, vol. 31, no. 2, pp. 131138,2008

[27] CPCS. U.S. Consumer Product Safety Commission.Toxicity Reviews of Di-(2-Ethylhexyl) Phthalate (DEHP), vol. 51, 2010.

[28] N. C. T. van Grieken, G. A. Meijer, A. Zur Hausen, S. G. M. Meuwissen, J. P. A. Baak, and E. J. Kuipers, "Increased apoptosis in gastric mucosa adjacent to intestinal metaplasia," Journal of Clinical Pathology, vol. 56, no. 5, pp. 358-362, 2003.

[29] H. H.-X. Xia and N. J. Talley, "Apoptosis in gastric epithelium induced by Helicobacter pylori infection: implications in gastric carcinogenesis," American Journal of Gastroenterology, vol. 96, no. 1, pp. 16-26, 2001.

[30] S. Tiwari, U. Ghoshal, U. C. Ghoshal et al., "Helicobacter pyloriinduced apoptosis in pathogenesis of gastric carcinoma," Indian Journal of Gastroenterology, vol. 24, no. 5, pp. 193-196, 2005.
[31] T. Guo, J.-M. Qian, J.-Z. Zhang, X.-B. Li, and Y.-Q. Zhao, "Effects of Helicobacter pylori and Helicobacter pylori-related cytokines on apoptosis of gastric epithelial cells and mechanisms thereof," National Medical Journal of China, vol. 86, no. 38, pp. 2670-2673, 2006.

[32] Z.-F. Liu, C.-Y. Chen, W. Tang, J.-Y. Zhang, Y.-Q. Gong, and J.H. Jia, "Gene-expression profiles in gastric epithelial cells stimulated with spiral and coccoid Helicobacter pylori," Journal of Medical Microbiology, vol. 55, no. 8, pp. 1009-1015, 2006.

[33] K.-M. Kim, S.-G. Lee, J.-M. Kim et al., "Helicobacter pylori $\gamma$-glutamyltranspeptidase induces cell cycle arrest at the G1-S phase transition," The Journal of Microbiology, vol. 48, no. 3, pp. 372-377, 2010.

[34] G. K. Anagnostopoulos, D. Stefanou, E. Arkoumani et al., "Bax and $\mathrm{Bcl}-2$ protein expression in gastric precancerous lesions: immunohistochemical study," Journal of Gastroenterology and Hepatology, vol. 20, no. 11, pp. 1674-1678, 2005.

[35] F. Bir, N. Calli-Demirkan, A. C. Tufan, M. Akbulut, and N. L. Satiroglu-Tufan, "Apoptotic cell death and its relationship to gastric carcinogenesis," World Journal of Gastroenterology, vol. 13, no. 23, pp. 3183-3188, 2007.

[36] H.-F. Liu, W.-W. Liu, G.-A. Wang, and X.-C. Teng, "Effect of Helicobacter pylori infection on Bax protein expression in patients with gastric precancerous lesions," World Journal of Gastroenterology, vol. 11, no. 37, pp. 5899-5901, 2005.

[37] M. Gryko, A. Pryczynicz, K. Guzinska-Ustymowicz et al., "Immunohistochemical assessment of apoptosis-associated proteins: p53, Bcl-xL, Bax and Bak in gastric cancer cells in correlation with clinical and pathomorphological factors," Advances in Medical Sciences, vol. 57, no. 1, pp. 77-83, 2012.

[38] R. C. Budd, W.-C. Yeh, and J. Tschopp, "cFLIP regulation of lymphocyte activation and development," Nature Reviews Immunology, vol. 6, no. 3, pp. 196-204, 2006.

[39] R. J. Youle and A. Strasser, "The BCL-2 protein family: opposing activities that mediate cell death," Nature Reviews Molecular Cell Biology, vol. 9, no. 1, pp. 47-59, 2008.

[40] J. Rudi, D. Kuck, S. Strand et al., "Involvement of the CD95 (APO-1/Fas) receptor and ligand system in Helicobacter pyloriinduced gastric epithelial apoptosis," Journal of Clinical Investigation, vol. 102, no. 8, pp. 1506-1514, 1998.

[41] S. Maeda, H. Yoshida, Y. Mitsuno et al., "Analysis of apoptotic and antiapoptotic signalling pathways induced by Helicobacter pylori," Gut, vol. 50, no. 6, pp. 771-778, 2002.

[42] M. Mukai, T. Kusama, Y. Hamanaka et al., "Cross talk between apoptosis and invasion signaling in cancer cells through caspase-3 activation," Cancer Research, vol. 65, no. 20, pp. 91219125, 2005.

[43] N. Isobe, H. Onodera, A. Mori et al., "Caspase-3 expression in human gastric carcinoma and its clinical significance," Oncology, vol. 66, no. 3, pp. 201-209, 2004.

[44] H.-C. Zheng, J.-M. Sun, Z.-L. Wei, X.-F. Yang, Y.-C. Zhang, and Y. Xin, "Expression of Fas ligand and Caspase-3 contributes to formation of immune escape in gastric cancer," World Journal of Gastroenterology, vol. 9, no. 7, pp. 1415-1420, 2003.

[45] S. Koyama, "Differential expression of intracellular apoptotic signaling molecules in tumor and tumor-infiltrating lymphocytes during development of invasion and/or metastasis of gastric carcinoma," Digestive Diseases and Sciences, vol. 48, no. 12, pp. 2290-2300, 2003. 


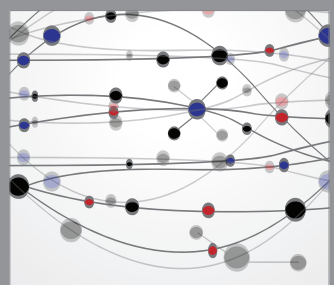

The Scientific World Journal
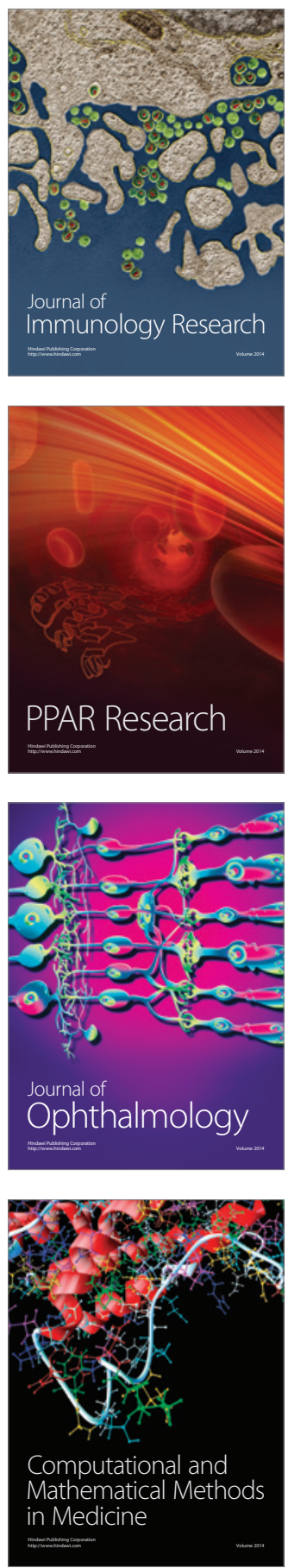

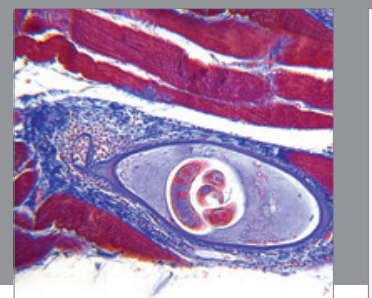

Gastroenterology

Research and Practice
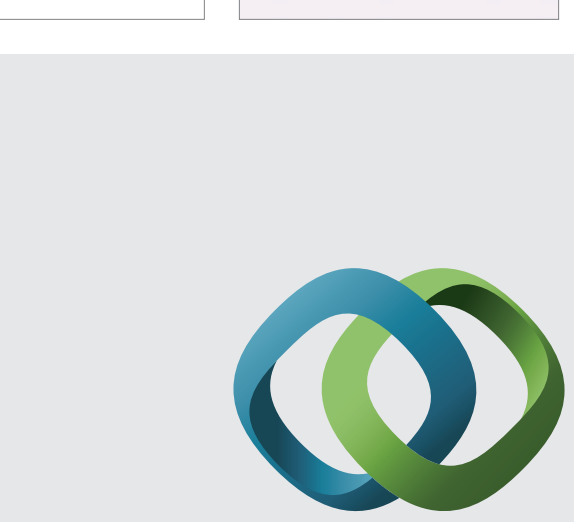

\section{Hindawi}

Submit your manuscripts at

http://www.hindawi.com
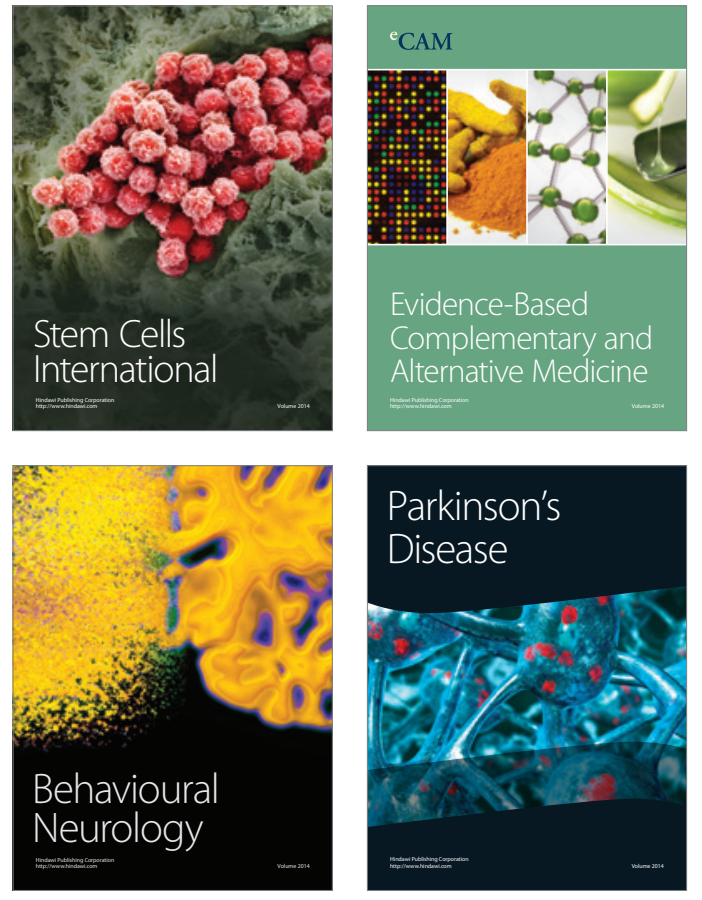
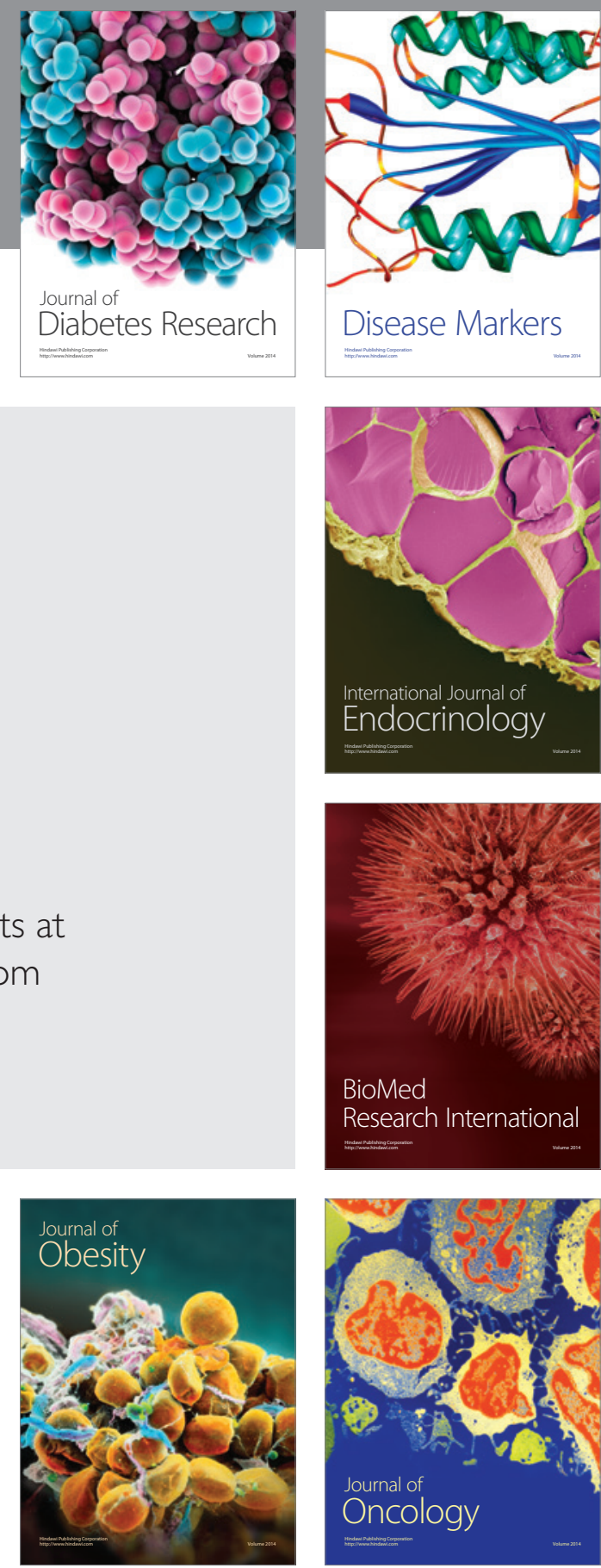

Disease Markers
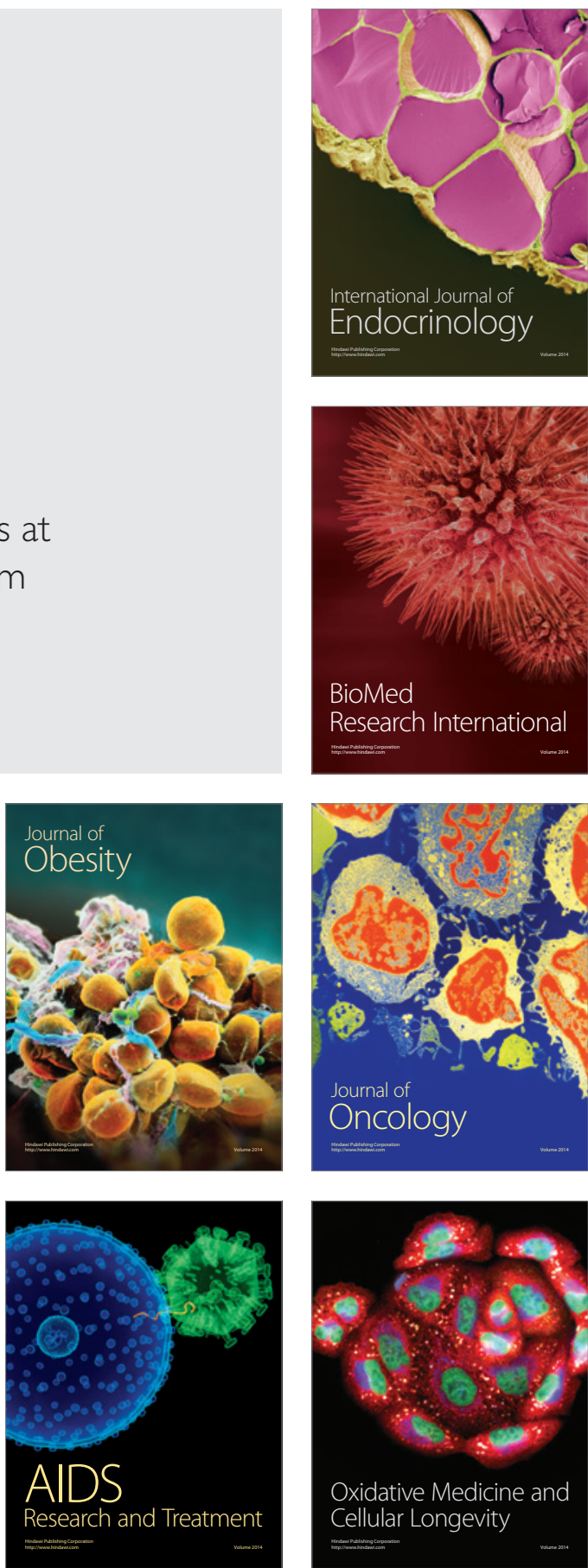